Running title: MEASURING THE CONDITION OF SALINE WETLANDS

\title{
Measuring the Condition of Saline Wetlands Threatened by Agricultural
}

\section{Intensification $^{* 1}$}

C. CASTAÑEDA and J. HERRERO

Soils and Irrigation Department, Agri-Research Center of Aragon, PO Box 727, 50080 Zaragoza, Spain. E-mail: jhi@aragon.es

\section{ABSTRACT}

The saline wetlands, or "saladas", of Monegros Desert, NE Spain, contain biodiversity that depends on the establishment of a prognostic monitoring system that can warn of approaching irreversible damage. In the context of a lack of existing biodiversity inventories for the saladas, we have determined their state of conservation and vulnerability using seven physical indicators: escarpment continuity, cropping, stone dumping, size, water occurrence, distance to roads, and proximity to irrigated areas. These features are combined into three meaningful indexes, i.e., conservation, current vulnerability, and future vulnerability, thus creating an assessment of the preservation or degradation of saladas in the context of encroaching agricultural irrigation projects. The proposed indexes produced consistent results and showed that a great number of the Monegros wetlands are threatened, regardless of their size or frequency of water occurrence. Only $20 \%$ of the saladas studied are classified as being in a good or very good conservation, whereas $50 \%$ are in bad or very bad shape. A high

\footnotetext{
${ }^{* 1}$ The Spanish Ministry of Education and Science supported this work with the research Project AGL2006-01283 and with the grant EX2006-0347 to the first author.
} 
current vulnerability was found for $60 \%$ of the saladas. For saladas located in land to be irrigated, we predict $73 \%$ will have a high or very high future vulnerability. Currently, $58 \%$ of the saladas are in bad or very bad condition and fully $65 \%$ of the saladas, variable in size, present a bad or very bad prognosis. Our approach provides a monitoring strategy for the conservation of saline wetlands threatened by agricultural intensification, especially irrigation.

Key Words: agricultural landscape, desert, irrigation, Monegros, playa.

\section{INTRODUCTION}

The degradation or loss of native wetlands is a matter of major environmental concern worldwide because of the significant biodiversity and the hydrological utility of these lands. Beyond the many physical threats to wetlands already identified, the scientific literature also describes how lack of information, historical legacies of land use and tenure, and political obstacles constrain conservation efforts (Naranjo, 1995; Davis and Froed, 1999; Finlayson and Rea, 1999; Smith, 2003; Uluocha and Okeke, 2004; Junk and Piedade, 2004).

Ecologists have developed indicators which enable them to describe environments with a complexity of components, as in Dale and Beyeler (2001), Tiner (2004), or Müller et al. (2006). Using natural and anthropogenic indicators, Klijn and Udo de Haes (1994) introduced abiotic ecosystem classifiers in the Netherlands. In non-ecological situations, abiotic indicators based on soil and geological processes and on geomorphologic features have been used to study the sustainability and the productivity of land (Cendrero et al., 2003) and to assess environmental impact (Rivas et al., 1997). Several sets of environmental indicators have been proposed by international agencies (OECD, 2003; EEA, 2004; UNEP, 2004). In Europe, recent studies have sought to establish indicators 
that can be processed by a geographic information system with the aim of monitoring Natura 2000 Habitats (Boteva et al., 2004; Langanke et al., 2005; Lang and Langanke, 2005).

Wetlands, as sensitive environments, require specific diagnostic indicators. Numerous visual features have been considered and ecological indicators have been developed (i) to identify morphological features and to quantify geomorphic attributes (Jurmu and Andrle, 1997; Adamowicz and Roman, 2005); (ii) to detect alterations of hydrological functions (Hruby, 2001; Lichvar et al., 2004; Cole, 2006); (iii) to assess the ecosystem integrity based on biological metrics (Cohen et al., 2005) or on remote sensing surveys (Phillips et al., 2005); or, (iv) to define the components of conceptual models for restoration (Mayer et al., 2004). An operational synthesis of the above approaches, the Wetland Rapid Assessment Procedure (WRAP) was adapted by Breaux et al. (2005). Of the wetland assessment methods reviewed by Fennesy et al. (2004), only the WRAP allowed rapid measurement that is conducted on site and is verifiable. Frequently, wetlands are rated using outside evaluators (Hruby, 2001; Breaux et al., 2005). These methods were conceived for humid countries, i.e., where there is permanent, fresh water; these metrics are not suitable for arid lands. Moreover, these assessment tools depend strongly on databases with site information, which is not the case for our study area or for many other arid lands.

Due to their scientific and ecological importance, half of the saladas territory has been classified by the local government as habitats to be included in the European Natura2000 network. The remainder of the saladas territory is being transformed for irrigation purposes (a project is set to irrigate over 60000 ha in southern Monegros). The irrigation works, which will supply water from Pyrenean rivers, will be managed by the local government. For 10 years the project has been on hold, as European Union 
funds have been blocked by the lobbying efforts of ecology activists. The project involves serious landscape transformations due to farm consolidation and the works associated with agricultural intensification.

The aim of this paper is to set up useful indicators and indexes to assess the conservation, vulnerability and prognosis of the Monegros saline wetlands. For this purpose we use explicit criteria that are adaptable to changes in the area, and to other arid lands. This integrated procedure can easily be applied to other wetlands in arid environments.

\section{STUDY AREA}

Saline wetlands are found in the Monegros desert, one of the most arid regions of Europe (Herrero and Snyder, 1997). Rainfall is very irregular, with a minimum annual average of $175 \mathrm{~mm}$, a maximum of $535 \mathrm{~mm}$, and an average of $354 \mathrm{~mm}$ recorded by the Petris Weather Station for the period 1973-2006. The mean annual $\mathrm{ET}_{0}$ is $1255 \mathrm{~mm}$, based on the estimate of Faci and Martínez-Cob (1991) for the nearby Bujaraloz Weather Station.

These saline depressions are scattered across a structural geological platform which is almost $200 \mathrm{~m}$ above the Ebro River water level, forming an endorheic complex closely connected to the hypersaline aquifers. Their name "salada" refers to the presence of salts in soils, surface water and groundwater, and also reminds one of their past use as salterns. They could be classified as depressional, isolated wetlands according to the Leibowitz and Nadeau (2003) definition. The saladas are fed primarily by groundwater. Their seasonal dry-wet cycles are relevant for their biodiversity and the endemic organisms that have adapted to fluctuations of brine level and chemistry. Halophilous vegetation, scarcely represented in the European inlands, appears in concentric fringes according to salinity tolerance, water availability and soil texture; the center of the 
wetland remains bare due to salinity and flooding. Elaboration of detailed maps of priority habitats and endemic vegetation in each salada are in progress (Domínguez et al., 2006).

More than a hundred saladas were inventoried in the region two decades ago. Of these, only 53 (Fig. 1) were recognized in our updated Inventory 2003 (Castañeda and Herrero, in revision). Ranging from less than 1 ha to more than 200 ha, the saladas lie hidden in the agricultural landscape, occupying the lowest positions of the gentle undulated topography. The saladas bottom elevation ranges between 310 and $370 \mathrm{~m}$ a.s.l. and they are shaped by escarpments of up to twenty meters tall which are aligned in the prevalent tectonic and wind direction, NW-SE.

The total surface of the saladas, almost 1000 ha, represents less than $3 \%$ of the whole agricultural platform. The platform is under dry farming, often surpassing the natural limits imposed by intermittent water occurrence in the saladas or by soil salinity, with winter cereal crops in soils having an electrical conductivity of $4 \mathrm{dS} \mathrm{m}^{-1}$ in the top soil layer $(0-60 \mathrm{~cm})$. The subsidies for rainfed cereal crops encouraged the agricultural invasion of marginal lands. As a result, recent decades have seen the disappearance and deterioration of some wetlands. Land consolidation, new roads, new power lines, drainage pipes and trenches, irrigation ponds, machinery traffic, and other construction are changing the appearance of the area, reducing the native vegetation and smoothing the salada escarpments, as observed during the field campaigns. Moreover, the close proximity of currently irrigated lands in the northern part of the platform (Fig. 1) and their projected extension towards the south will disturb their hydrological cycle. Several saladas are already artificially flooded with fresh and polluted water from the return flows of the newly irrigated lands.

[Fig. 1] 
We use the saladas Inventory 2003, (Castañeda, 2002, pages 33-37; Castañeda and Herrero, in revision) containing their conservation status, as established in the field using external expert judgment, and systematic descriptions of these saline wetlands obtained by ground surveys, remote sensing and orthophotographs (Table I). For the purposes of this article, we have added to the above database the water occurrence in each salada, and its proximity both to any new roads and to the border of the forthcoming irrigated area, which is delineated following arbitrary straight-line limits.

Following the ecosystem approach that is frequently used in wetland study, we integrated the selected perceptible components of the Monegros saladas at different scales, from the field survey to the satellite images analysis; then a spatial analysis was performed using a geographical information system (GIS) to provide a perspective difficult to obtain from field surveys alone.

Hydrology, geomorphology, and biology, were included in our examination of the Monegros saladas by means of the following interrelated perceptible components: water occurrence, the appearance of the depressions, and the preservation of native vegetation. Though it is important to protect and conserve extremophile microbes and endemisms, these and other intrinsic values can not be used for ranking because their study has just started (Domínguez et al., 2006). We merged crop and natural vegetation borders with abiotic elements to maximize measurement efficiency, validity and reliability. Usually the abiotic elements control the biotic ones; however, the geomorphic and hydrologic control of Monegros saladas has not been recognized in conservation policy. Moreover, the paucity of hydrology data and the lack of soil and vegetation maps have imposed the approach used here for studying the status of the saladas. 
In order to measure the status of the saladas in terms of conservation and vulnerability we have developed several indexes. We treat them jointly in a GIS database in order to assess the current condition of these wetlands and for monitoring programs. 
TABLE I

Main features registered in the Inventory 2003. (+): saladas detected in Landsat images.

Data obtained from: field observations ${ }^{(1)}$, remote sensing ${ }^{(2)}$, and GIS analysis ${ }^{(3)}$.

\begin{tabular}{|c|c|c|c|c|c|c|c|}
\hline Salada name & 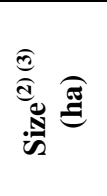 & $\begin{array}{l}\text { Conservation } \\
\text { Status }^{(1)}\end{array}$ & Escarpment $^{(1)}$ & Dumping $^{(1)}$ & Cropping $^{(1)}$ & 矛 & 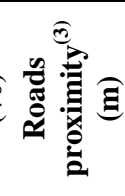 \\
\hline Agustín (+) & 68.1 & heavily disturbed & flat bottomed valley & center & partially & 27 & 384 \\
\hline Albacar (+) & 10.2 & pristine & unrecognizable & without & totally & 4 & 284 \\
\hline Alforjeta I (+) & 1.4 & slightly disturbed & unrecognizable & center & partially & 4 & 199 \\
\hline Alforjeta II & 2.3 & slightly disturbed & smooth & center & partially & & 199 \\
\hline Amarga Alta $(+)$ & 22.3 & advanced destruction & semi-confining & center and escarpment & partially & 27 & 395 \\
\hline Amarga Baja (+) & 7.1 & unrecognizable & semi-confining & center & without & 31 & 292 \\
\hline Balsa $(+)$ & 2.9 & heavily disturbed & smooth & escarpment & totally & 4 & 189 \\
\hline Benamud (+) & 19.9 & heavily disturbed & smooth & without & partially & 35 & 459 \\
\hline Berchel $(+)$ & 2.6 & pristine & unrecognizable & without & totally & 0 & 244 \\
\hline Bernab $(+)$ & 4.3 & heavily disturbed & smooth & center and escarpment & partially & 4 & 310 \\
\hline Berzas & 8.8 & disturbed & smooth & escarpment & totally & & 233 \\
\hline Camarón (+) & 44.7 & unrecognizable & confining & center and escarpment & without & 54 & 362 \\
\hline Catio I & 2.3 & slightly disturbed & smooth & escarpment & totally & & 164 \\
\hline Catio II (+) & 3.7 & slightly disturbed & unrecognizable & escarpment & partially & & 320 \\
\hline Cerrajero $(+)$ & 10.1 & pristine & unrecognizable & without & totally & 0 & 703 \\
\hline Chamarqueta $(*)$ & 0.5 & disturbed & smooth & escarpment & totally & & 215 \\
\hline clota-19 (+) & 1.7 & pristine & unrecognizable & without & totally & 0 & 388 \\
\hline clota-37 (+) & 4.9 & disturbed & smooth & without & totally & 4 & 302 \\
\hline clota-50 (+) & 2.5 & slightly disturbed & unrecognizable & center and escarpment & partially & 0 & 599 \\
\hline clota-51 (+) & 4.1 & heavily disturbed & unrecognizable & center & partially & 0 & 123 \\
\hline clota-52 & 2.8 & slightly disturbed & smooth & center & partially & & 351 \\
\hline clota-94 (+) & 9.3 & slightly disturbed & smooth & center & partially & 0 & 431 \\
\hline Corral Viejo $(+)$ & 4.9 & heavily disturbed & smooth & center and escarpment & without & 4 & 491 \\
\hline Correo & 4.6 & heavily disturbed & smooth & center and escarpment & partially & & 294 \\
\hline Don Roque $(+)$ & 10.0 & slightly disturbed & flat bottomed valley & center & partially & 12 & 533 \\
\hline Escobedo & 6.3 & disturbed & smooth & without & totally & & 194 \\
\hline Farnaca $(+)$ & 12.2 & heavily disturbed & flat bottomed valley & center & partially & 19 & 210 \\
\hline Gramenosa $(+)$ & 10.7 & unrecognizable & confining & center and escarpment & without & 4 & 462 \\
\hline Gros & 3.9 & heavily disturbed & flat bottomed valley & center and escarpment & partially & & 241 \\
\hline Guallar (+) & 15.0 & unrecognizable & semi-confining & center and escarpment & partially & 58 & 278 \\
\hline Herrero & 3.2 & heavily disturbed & smooth & escarpment & partially & & 296 \\
\hline Hoya del Pez & 2.5 & pristine & unrecognizable & center & without & & 331 \\
\hline La Playa $(+)$ & 234.5 & unrecognizable & confining & center and escarpment & without & 50 & 601 \\
\hline Larga & 10.4 & heavily disturbed & flat bottomed valley & center & partially & & 275 \\
\hline Lisonfer & 5.5 & heavily disturbed & smooth & center and escarpment & partially & & 318 \\
\hline Muerte $(+)$ & 17.9 & unrecognizable & semi-confining & center and escarpment & without & 58 & 303 \\
\hline Nieves $(+)$ & 7.0 & pristine & smooth & center and escarpment & totally & 0 & 251 \\
\hline $\operatorname{Pez}(+)$ & 8.3 & unrecognizable & semi-confining & without & without & 23 & 502 \\
\hline Piñol (+) & 15.7 & unrecognizable & confining & center & without & 35 & 459 \\
\hline Pitamar (+) & 4.2 & pristine & unrecognizable & center and escarpment & partially & & 296 \\
\hline Pito & 67.2 & unrecognizable & confining & escarpment & without & 35 & 565 \\
\hline Pueyo (+) & 24.3 & unrecognizable & confining & escarpment & without & 38 & 421 \\
\hline Rebollón (+) & 16.1 & advanced destruction & semi-confining & center and escarpment & partially & 27 & 651 \\
\hline Rollico (+) & 40.3 & advanced destruction & semi-confining & center and escarpment & totally & 38 & 810 \\
\hline Salineta $(+)$ & 22.7 & unrecognizable & confining & escarpment & without & 100 & 430 \\
\hline San Miguel (+) & 10.4 & pristine & unrecognizable & center & partially & 0 & 506 \\
\hline Valdecarreta $(+)$ & 6.9 & heavily disturbed & flat bottomed valley & center and escarpment & partially & & 244 \\
\hline Valdefrancín & 25.7 & disturbed & flat bottomed valley & center and escarpment & totally & & 354 \\
\hline Valdespartosa $(+)$ & 14.8 & heavily disturbed & flat bottomed valley & center & partially & 8 & 442 \\
\hline Vinagrero I (+) & 5.0 & slightly disturbed & flat bottomed valley & center and escarpment & partially & 4 & 434 \\
\hline Vinagrero II $(+)$ & 5.0 & slightly disturbed & flat bottomed valley & center and escarpment & partially & 4 & 249 \\
\hline Yesera I (+) & 3.1 & slightly disturbed & smooth & center & partially & 0 & 252 \\
\hline Zaborros (+) & 9.0 & slightly disturbed & smooth & without & totally & 4 & 147 \\
\hline
\end{tabular}




\section{Indicators, criteria and rating}

Observations of escarpment, stone dumping, cropping, salada size and water occurrence were used because they are the most outstanding features of these wetlands and because these features are easily observed and interpreted. The distance to roads and future irrigated developments were included as the main conveyors of human pressure. Escarpment indicates the confinement of the salada: the higher and more continuous is the escarpment, the better the salada preservation. Usually the escarpment slope is not homogeneous; the northern and southern borders are higher and/or more continuous while salada borders are typically open to the east and the west (Gutiérrez et al., 2002). About $44 \%$ of the saladas have a smooth or unrecognizable escarpment. Cropping indicates degradation and implies the destruction of native vegetation fringes, the alteration of soil, modified run-off, increased erosion and sedimentation in playas (Haukos and Smith, 1994). Moreover, native vegetation lost to cropping is also lost as a monitoring tool (Finlayson and Rea, 1999). Stone dumping is also an indicator of degradation, affecting $77 \%$ of the saladas; stones removed from surrounding fields are dumped over the escarpment, or spread in piles over the vegetated bottom or the mud flat. More than $80 \%$ of the saladas are affected by stone dumping.

Salada size was obtained from satellite images and orthophotomaps. Size ranges from 0.5 ha to 235 ha, with a median of 7.1 ha. From a developmental point of view, the enlargement of the saladas is related to their maturity; therefore, size is noticeably related to the escarpment and the presence of water, and indirectly related to the risk of disappearance. In general, the largest saladas are the best preserved because they are flooded for some weeks every year; while other non-annually flooded saladas are covered with halophytes and are at risk from plowing to earn subsidies from the European Union. Water occurrence, an outstanding feature in this arid zone, 
represents aquifer discharge. This feature was the most frequently used metric in early studies of Monegros (Table II), but the lack of standard procedures hampers use of this indicator. The most suitable data source was remote sensing as it provides repetitive synchronic and synoptic observations, and spans the largest period of time. Remote sensing gives surface area, but as water extent cannot be measured in the field because the muddy bottoms are impassable, so our remotely sensed data were converted to presence/absence to allow continuity with field observations. This indicator is expressed as the percentage of satellite images with water in the 39 saladas (Table I) detected with Landsat images (Castañeda et al., 2005).

The distance to roads has been computed in order to establish different levels of human influence. Distances range from $810 \mathrm{~m}$ to $123 \mathrm{~m}$, with a median of $318 \mathrm{~m}$. Agricultural fields, previously formed as an irregular mosaic adapted to the roundshaped depressions and sinkholes, have become square-shaped due to land consolidation. The associated new road network has fragmented many saladas and has increased their exposure to machinery traffic; previously untrodden soils have been altered by compaction and are slow to recover, typical of arid regions (Belnap and Warren, 2002; Kade and Warren, 2002; Webb, 2002).

The proximity to the irrigated area was considered since it increases the risk of degradation, due to the earth movements and the flows from the irrigation. Also, some saladas are planned to host pumping stations and other hydraulic infrastructures. 


\section{TABLE II}

Number of wetlands listed by different authors, with the type of water observation, period and frequency of recording.

\begin{tabular}{lclll}
\hline \multirow{2}{*}{ Source } & Number of & Water observation & & \\
\cline { 3 - 5 } & surveyed & Type & Period & Frequency \\
\hline Comín and Sanz (1989) & 85 & presence / absence & 1988 & single record \\
Berga (1993) & 15 & presence / absence & $1989-1990$ & monthly \\
Castañeda (2002) & 8 & water depth & $1993-1997$ & weekly \\
Castañeda and Herrero (2005) & 39 & water surface & $1985-2000$ & semiannual \\
\hline
\end{tabular}

The type and the degree of changes to be expected in these wetlands are unknown; however, previous studies (García-Vera, 1996; Samper and García-Vera, 1998) predict the flooding and salinization of the soils unless drainage is installed. The technology of irrigation water distributed by pressurized pipes has resulted in the artificial segregation of the platform in non irrigated and irrigated land (Fig. 1) affecting many saladas according to the Irrigation Plan. We considered a buffer of $500 \mathrm{~m}$ as the area of influence around the future irrigated area. Irrigation effects are not ignored but cannot be included as an indicator, due to the lack of hydrogeological models for each salada.

The above observations are considered as the key indicators of preservation or degradation (Table III) together with the specific process defined by them. The indicators were categorized, and then rated using specific scales according to their significance. Since the indicators came from three different sources, i.e., field, remote sensing and cartography, a custom scheme was required to establish the categories. For these to be significant and helpful in determining the relative status of the saladas, the scales were set taking into account their correspondence with field evidence, and the nature of each indicator. To produce comparable index values, and to avoid disparate 
figures in some saladas, most indicators are integers scaled from one to five. Some scales included zero, negative or non-integer values. 


\section{TABLE III}

Set of indicators used in this study with their criteria and specific processes. The last two columns show the categories established for each indicator to describe the cases found in the saladas and the rating generated according to their significance.

\begin{tabular}{|c|c|c|c|c|}
\hline & Indicator & Criterion / process & Category & Rating \\
\hline \multirow{12}{*}{ 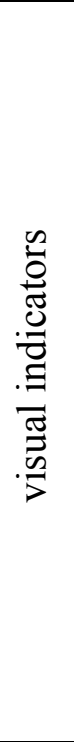 } & \multirow{5}{*}{$\begin{array}{l}\text { Escarpment } \\
\text { continuity and } \\
\text { height }\end{array}$} & \multirow{5}{*}{$\begin{array}{l}\text { Preservation / } \\
\text { confining and isolating }\end{array}$} & unrecognizable & 0 \\
\hline & & & smooth & 1 \\
\hline & & & $\begin{array}{l}\text { flat bottomed } \\
\text { valley }\end{array}$ & 2 \\
\hline & & & semi-confining & 3 \\
\hline & & & confining & 4 \\
\hline & \multirow{3}{*}{ Cropping } & \multirow{3}{*}{$\begin{array}{l}\text { Degradation / } \\
\text { destroying native vegetation } \\
\text { And altering soils properties }\end{array}$} & totally cultivated & -2 \\
\hline & & & partially cultivated & 1 \\
\hline & & & not cultivated & 5 \\
\hline & \multirow{4}{*}{ Stone dumping } & \multirow{4}{*}{$\begin{array}{l}\text { Degradation / } \\
\text { destroying native vegetation } \\
\text { and altering surface processes }\end{array}$} & completely covered & 1 \\
\hline & & & in center & 2 \\
\hline & & & in escarpment & 3 \\
\hline & & & absence & 5 \\
\hline \multirow{10}{*}{ 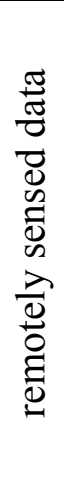 } & \multirow{5}{*}{ Size } & \multirow{5}{*}{$\begin{array}{l}\text { Preservation / } \\
\text { salinity and flooding } \\
\text { hampering plowing }\end{array}$} & $\leq 10$ ha & 1 \\
\hline & & & $10-20$ ha & 2 \\
\hline & & & $20-40$ ha & 3 \\
\hline & & & $40-70$ ha & 4 \\
\hline & & & $>200$ ha & 5 \\
\hline & \multirow{5}{*}{ Water occurrence } & \multirow{5}{*}{$\begin{array}{l}\text { Preservation / } \\
\text { hampering plowing }\end{array}$} & $>75 \%$ & 1 \\
\hline & & & $50-75 \%$ & 2 \\
\hline & & & $25-50 \%$ & 3 \\
\hline & & & $1-25 \%$ & 4 \\
\hline & & & $0 \%$ & 5 \\
\hline \multirow{8}{*}{ 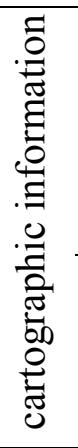 } & \multirow{5}{*}{$\begin{array}{l}\text { Proximity to roads } \\
\text { in intervals of } 200 \mathrm{~m}\end{array}$} & \multirow{5}{*}{$\begin{array}{l}\text { Degradation / } \\
\text { irrigation works } \\
\text { And traffic proximity }\end{array}$} & $0-200$ & 1 \\
\hline & & & $200-400$ & 2 \\
\hline & & & $400-600$ & 3 \\
\hline & & & $600-800$ & 4 \\
\hline & & & $>800$ & 5 \\
\hline & \multirow{3}{*}{$\begin{array}{l}\text { Proximity to the } \\
\text { future irrigated area }\end{array}$} & \multirow{3}{*}{$\begin{array}{l}\text { Degradation / } \\
\text { irrigation works, } \\
\text { flooding with fresh } \\
\text { And polluted water }\end{array}$} & inside & 1 \\
\hline & & & $<500 \mathrm{~m}$ far & 1.2 \\
\hline & & & $>500 \mathrm{~m}$ far & 1.5 \\
\hline
\end{tabular}




\section{Proposed Indexes}

A conservation index (CI) was established as a linear combination of the three visual indicators (Table III) weighted as following:

$$
C I=3 \times\{\text { escarpment }\}+2 \times\{\text { cropping }\}+1.5 \times\{\text { stone } \cdot \text { dumping }\}
$$

where $\{$ escarpment $\},\{c r o p\}$ and $\{$ stone dumping $\}$ are the scaled indicators. The weight assigned to each indicator was tested and tuned in successive trials by examining the agreement with the current status of the saladas determined in the field by external expert as part of the Inventory 2003 (Castañeda and Herrero, in revision). The agreement was measured with Spearman coefficient $(\mathrm{P}<0.05)$ on 25 saladas, and evaluated with the other 28 saladas.

Two indexes were established for measuring the exposure to degrading forces. First, in order to provide the degree of exposure to deterioration at present, a current vulnerability index (VIc) was created as

$$
\text { VIc }=\{\text { proximity } \cdot \text { to } \cdot \text { roads }\}+\{\text { size }\}+\{\text { water } \cdot \text { ocurrence }\}
$$

where \{proximity to roads\}, \{size $\}$ and $\{$ water occurrence $\}$ are the rated indicators. Taking into account the application of water during the life-time of the irrigation district, we predict this negative effect of the forthcoming irrigation in the area. Then, the proximity to the planned irrigated area is introduced (Table III), establishing the predictable future vulnerability index (VIf) as

$$
V I f=\varphi \times V I c
$$

where $\varphi$ takes one of three values, depending of the location of each salada (Table III).

The resulting values of the above indexes were grouped in intervals using the natural-breaks classification method (Jenks, 1977). Each interval was represented by a code and its corresponding level of the thematic meaning (Table IV). 


\section{TABLE IV}

Intervals established for the Conservation Index (CI), the Current Vulnerability Index (VIc), and the Future Vulnerability Index (VIf); code assigned, and their thematic value.

\begin{tabular}{lllll}
\hline Index & Intervals & Code & Thematic value & \\
\hline & $0.5-5.5$ & 1 & & very bad \\
& $5.6-8.0$ & 2 & & bad \\
CI & $8.1-14.5$ & 3 & Conservation status & fair \\
& $14.6-22.0$ & 4 & & good \\
& $22.1-26.5$ & 5 & & very good \\
\hline \multirow{2}{*}{ VIc } & $6.0-8.9$ & 1 & & low \\
& $9.0-11.9$ & 2 & Current vulnerability & fair \\
& $12.0-15.9$ & 3 & & high \\
\hline & $6.0-8.9$ & 1 & & low \\
VIf & $9.0-11.9$ & 2 & Future vulnerability & fair \\
& $12.0-15.9$ & 3 & & high \\
& $16.0-22.5$ & 4 & & very high \\
\hline
\end{tabular}

Finally, conservation and vulnerability indexes were linked to obtain an integrated index of the salada condition (SCI). By crossing CI with VIc and VIf, we obtained the current condition (SCIc) and the future condition (SCIf), respectively. Each combination that was encountered of Conservation Index with Current Vulnerability Index and with Future Vulnerability Index was assigned a value (Table V). 


\section{TABLE V}

In grey shading, values assigned to the saladas condition (SDS) according to a combination of Conservation and Vulnerability values.

\begin{tabular}{llll}
\hline \multirow{2}{*}{ Conservation status } & \multicolumn{2}{l}{ Current vulnerability } \\
\cline { 2 - 4 } & low & medium high \\
\hline very bad & $*$ & bad & very bad \\
bad & $*$ & bad & very bad \\
fair & $*$ & fair & very bad \\
good & very good & good & fair \\
very good & very good good & fair \\
\hline
\end{tabular}

\begin{tabular}{|c|c|c|c|}
\hline \multicolumn{4}{|c|}{ Future vulnerability } \\
\hline low & medium & high & very high \\
\hline$*$ & * & very bad & very bad \\
\hline$*$ & $*$ & very bad & very bad \\
\hline$*$ & $\mathrm{Bad}$ & very bad & very bad \\
\hline very good & good & fair & $*$ \\
\hline very good & good & fair & fair \\
\hline
\end{tabular}

\section{RESULTS AND DISCUSSION}

The state of conservation of the saladas

The \{escarpment $\}$ had the highest significance as observed in the field: it has favored the preservation of saladas by making it difficult for machinery to invade the salada. \{Stone dumping $\}$ had the lowest power in differentiating degradation, as it affects all the saladas. \{Cropping\} had an intermediate level of significance and depends in part on the escarpment. 
The CI values had a slight positive relationship with the water occurrence with a Pearson correlation coefficient of $r=0.78(p=0.000)$ and had no observed relation $(r=$ $0.39 ; \mathrm{p}=0.15$ ) to the size of the salada (Fig. 2). Even when the more frequently flooded saladas yield high values of CI, the weak relationships denote an anthropic control of the conservation state rather than a natural one.

[Fig. 2]

From the thematic values (Table IV), 20\% of the saladas are in good or very good conservation (Fig. 3); they are of playa-lake type, holding water at least some time each year. Almost all of them are surrounded by crops and are affected by stone dumping to different degrees. Half of the saladas have a bad or very bad conservation; these are primarily the smallest saladas and those strongly influenced by cropping; of these, nine have been completely plowed and nine more are unrecognizable because of stone dumping, debris, and construction. Some $30 \%$ of the saladas present a fair conservation, with a smooth escarpment and the bottom covered by halophytes. Their soils, with an electrical conductivity $>100 \mathrm{dS} \mathrm{m}^{-1}$ (Herrero, 1982), are considered unproductive by the rural population; this has facilitated their conservation, except for stone dumping.

[Fig. 3]

\section{Vulnerability of the saladas}

The current vulnerability index (VIc) represents the common vulnerability for all the saladas since it computes the effects of land consolidation and machinery traffic. When roads are adjacent to the saladas, they increase stone dumping, debris, and earth movements. This is the case of the saladas Amarga Baja and Muerte, where the native vegetation and the dune formed leeward have been partially destroyed. Moreover, other 
saladas have been crisscrossed by new roads, disturbing the hydrological function of the wetland.

This VIc index was applied to the 39 saladas detected by remote sensing. Following the thematic values of Table IV, $60 \%$ of these saladas have a high current vulnerability (Fig. 4); they are the smallest saladas, ranging from 1.4 to 12.2 ha, and have the least water occurrence. They usually have smooth escarpment but halophytes remain in spite of stone dumping and cropping. Some of them are very close to or are within the irrigated area.

[Fig. 4]

We found that $28 \%$ of the saladas studied present a fair current vulnerability; some are outside the planned irrigation area. Within the irrigated area, saladas Agustín, Benamud and Gramenosa have less water occurrence; they are the most representative of those saladas hosting some of the priority habitats listed by the Habitats Directive (97/62CEE) of the European Union. Only 13\% present a low vulnerability; they are the largest playas and all but one will remain outside the irrigated area.

The VIf yields a number of saladas exposed to a risk of degradation higher than the VIc (Fig. 5). We found that $73 \%$ have a high or very high prognosis of future vulnerability. Only the largest playas (10\%) have a diagnosis of low future vulnerability. The predicted vulnerability index value is fair for the most frequently flooded wetlands; however, alteration of dry-wet cycles and chemical characteristics can be foreseen for those closely surrounded by irrigated fields. Fig. 5 shows the difference between the current (VIc) and the future (VIf) vulnerability indexes. We predict that almost all the small saladas in the southern part will suffer an increase in their vulnerability, as well as the Agustín, Farnaca and Benamud saladas.

[Fig. 5] 
The ongoing irrigation works are producing effects in agreement with the VIf categories (Fig. 6). Much more intense alteration is expected when irrigation starts, due to foreseeable irrigation returns and other water flows.

\section{[Fig. 6]}

As shown in Fig. 7, the relationships between the vulnerability indexes (VIc and VIf) and the water occurrence or the size of the saladas yield negative Pearson correlation coefficients. The only significant, but slight, correlations are water occurrence with VIf $(r=-0.73 ; p=0.000)$, and size with VIc $(r=-0.24 ; p=0.009)$. These slight correlations parallel that of the CI (Fig. 2) and highlight the rise of anthropic influence. The highest vulnerability values occur in saladas $<10$ ha, which are also those with less water occurrence.

\section{[Fig. 7]}

\section{Condition of the saladas}

A separate assessment of the conservation status (CI) and the current and future vulnerabilities (VIc and VIf, respectively) can be used for designing conservative or preventive strategies. The integration of these indexes in the current and future condition of the saladas, SCIc and SCIf, respectively, provides (Figs. 8 and 9) a comprehensive qualification of the saladas that can illustrate the effects produced by advancing irrigation. Obviously, the best situation corresponds to those saladas having the highest state of conservation and the lowest vulnerability.

After applying values (Table V), more than a half of saladas, some $58 \%$, have a bad or very bad current condition. They are the smallest, less than 13 ha, and were without water presence on the dates the satellite images were obtained. Some of them are unrecognizable due to cropping. 
[Figs. 8, 9]

A good or very good current condition was determined for $28 \%$ of the saladas. These are the largest playa-lakes. Also, Benamud and Gramenosa are classified as in good condition in spite of being dry on the dates studied. From among the $15 \%$ of saladas with a fair current condition, Agustín, Las Amargas and Valdespartosa are of medium size and they stand out because of their valuable halophilous vegetation, scarcely represented in inland wetlands of Europe.

The prognosis is worse for the saladas located near or within the irrigated area. Some of these saladas are medium sized and have a very good conservation; however, since they occupy the lowest topographic positions, they are destined to become drainage ponds, permanently flooded with less saline, polluted waters.

Summarizing, $65 \%$ of the saladas, variable in size, have a bad or very bad predicted future condition; the majority of these are close to or within the irrigated area. The best future condition is predicted for $28 \%$ of the lot, among them the following playa-lakes: La Playa, Pueyo, Pito, Guallar, Muerte, Piñol, Camarón, Rebollón, and Rollico. Others such as Salineta, Agustín and Gramenosa will be the most affected by irrigation plans in spite of their current very good conservation.

The resulting scores, good, very good, bad and so on do not measure absolute values or have intrinsic meaning, but they do allow for comparisons among saladas and provide an understand of the status and threat to these wetlands. These descriptors can be used to choose conservation measures or to evaluate the resilience of the lakes. The better the condition of the saladas, the less effort required to conserve them. In the case of very bad condition, intervention would be useless and ineffective because the saladas are probably unrecoverable. The GIS database includes historical and current homogenized data for these wetlands and is prepared to integrate data from future 
surveys. The standardized monitor procedures presented here can help insure that public policies targeting the saladas are in fact achieving their goals.

\section{CONCLUSIONS}

The methodology here developed yields a coherent ranking of the saladas according to their conservation and their vulnerability, validated with expert judgment. The use of easily observable features allows for the rapid and, consistent assessment of the condition of the saladas and also provides warning signals of current and future threats to these habitats. Only $20 \%$ of the saladas studied are in a good or very good state of conservation; $30 \%$ of them are in fair state; half of the saladas are in a bad or very bad state, primarily the smallest and those largely invaded by cropping. From the saladas studied, $60 \%$ of them have high current vulnerability; they are the smallest saladas and those with a lower water occurrence; $28 \%$ present a fair current vulnerability and $13 \%$, the largest playa-lakes, are of low vulnerability. The prognosis on the effect of the irrigation plan on these wetlands is that $73 \%$ would have a high or very high future vulnerability. Only $10 \%$ have a low future vulnerability, the largest playa-lakes of the center and southern sections of the region.

A majority, $58 \%$ of saladas, are in bad or very bad condition. These are those of less than 13 ha, and without water presence on the dates studied; $28 \%$ are in good or very good current condition and $15 \%$ are in a fair current condition. Finally, $65 \%$ of the saladas, variable in size, are predicted to have a bad or very bad future condition; the majority of this group is close to or within the irrigated area. The best future condition is predicted for $28 \%$ of the saladas, found in the southwestern quadrant. Salineta, Agustín, and Gramenosa are in a very good conservation state and are very highly vulnerable: these lakes can easily be saved. The conservation or the vulnerability are 
not reflected in any particular salada feature, such as size or flood frequency, because of the strong agricultural intensification in recent years.

This salada assessment allows us to establish priorities for surveillance, conservation, and restoration purposes. In general, the loss of saladas could be mitigated through the adoption of enhancement and restoration measures. Other criteria could be used depending on the point of view, the social demand, and the resources available to make observations. This methodology can be applied to other saline wetlands under agricultural or other human pressures.

\section{List of figures}

Fig. 1 Roads in 1988 (a), and new roads in 2003 (b), superimposed to the August Landsat image of 5TM and ETM+ sensors, respectively (RGB 543). The currently irrigated area appears in green with this band combination

Fig. 2 Values of the salada Condition Index, CI, compared with water occurrence (a) and salada size (b).

Fig. 3 Conservation status of the saladas as established using the Conservation Index (CI) index, which was defined with three field features: escarpment, cropping, and stone dumping.

Fig. 4 The current vulnerability of the saladas as established using the Vulnerability Index (VIc), which was defined with three features extracted from remote sensing and GIS analysis: proximity to roads, size, and water occurrence.

Fig. 5 Predicted changes in the salada vulnerability when the planned irrigation is considered

Fig. 6 The future vulnerability of the saladas as established by the Future Vulnerability Index (VIf), which takes into account the future irrigated area extent. 
Fig. 7 Values of the two Vulnerability indexes — current (VIc) and future (VIf)compared with water occurrence(a) and salada size (b).

Fig. 8 The current condition of the saladas as established using the Saladas Condition Index (SCI), which takes into account conservation status and vulnerability.

Fig. 9 The future condition of the saladas using the SCIf index, which takes into account the irrigation plan. 


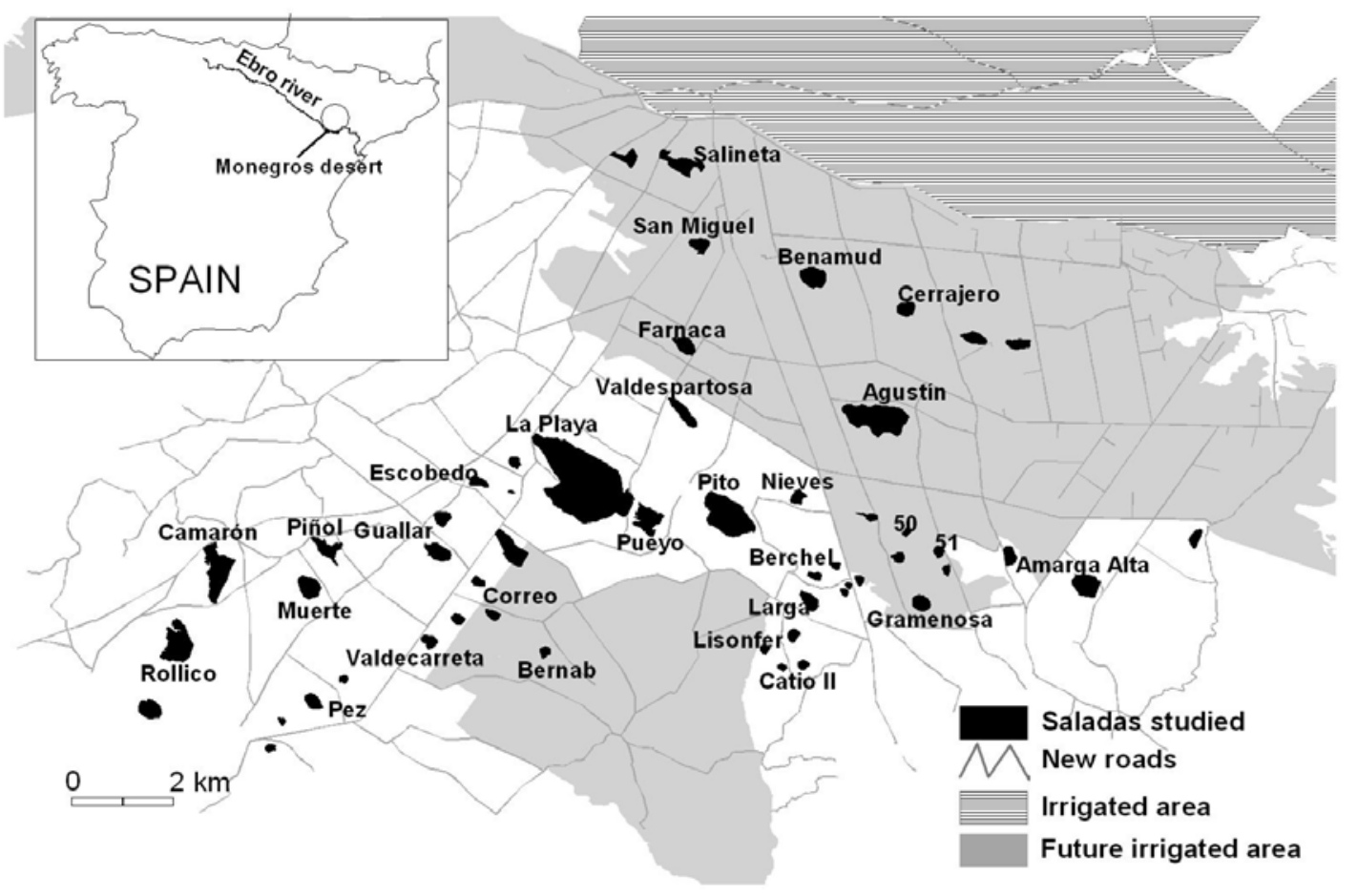



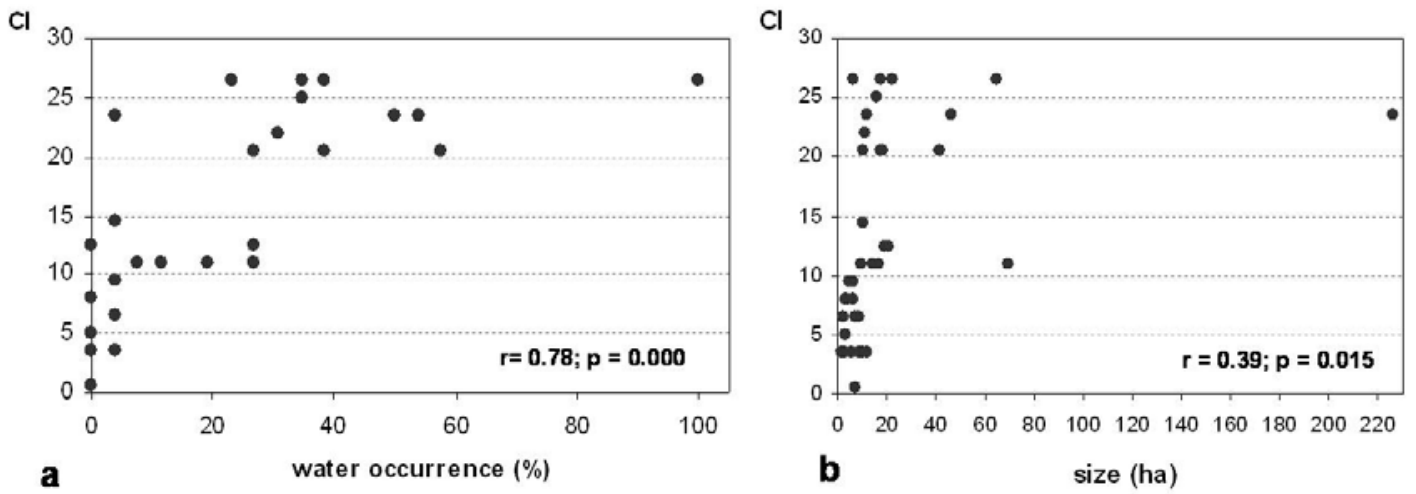


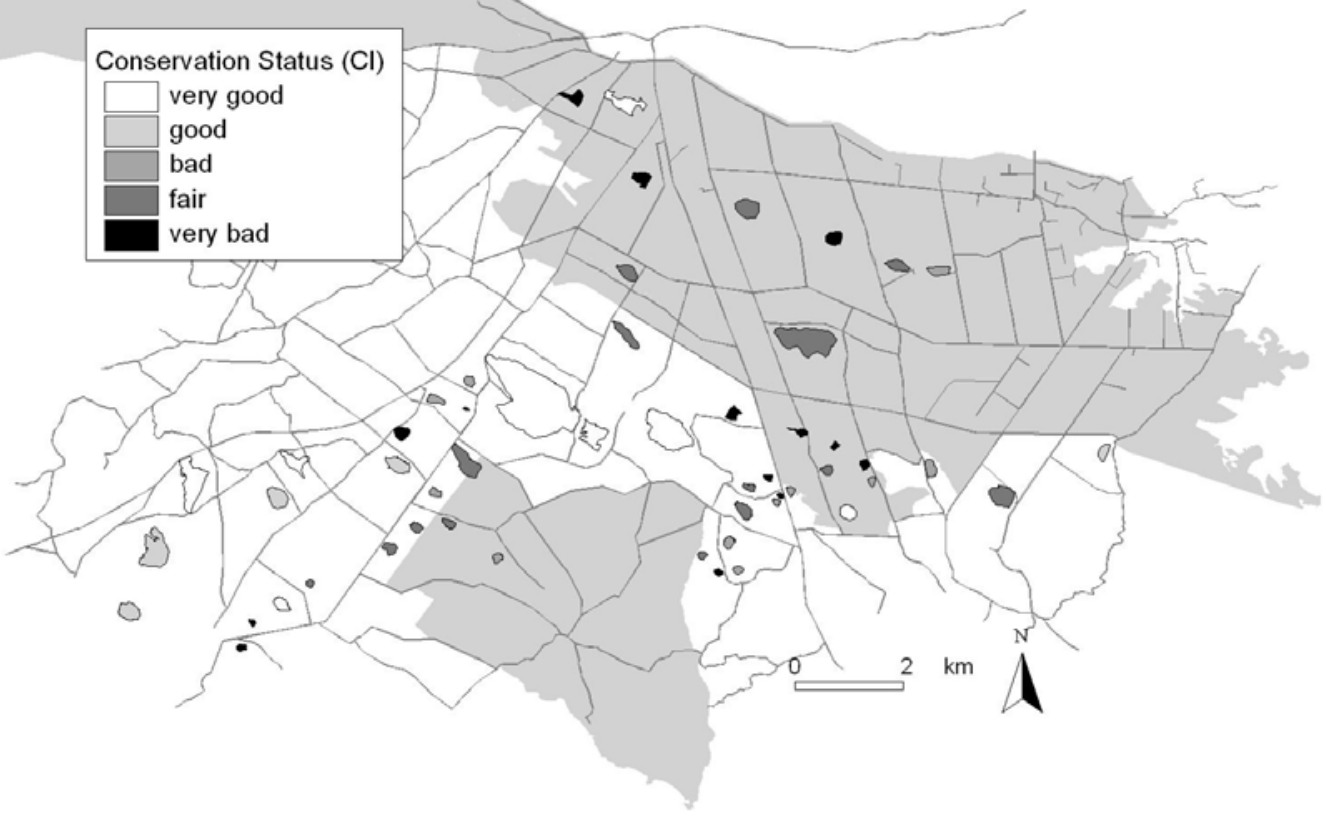




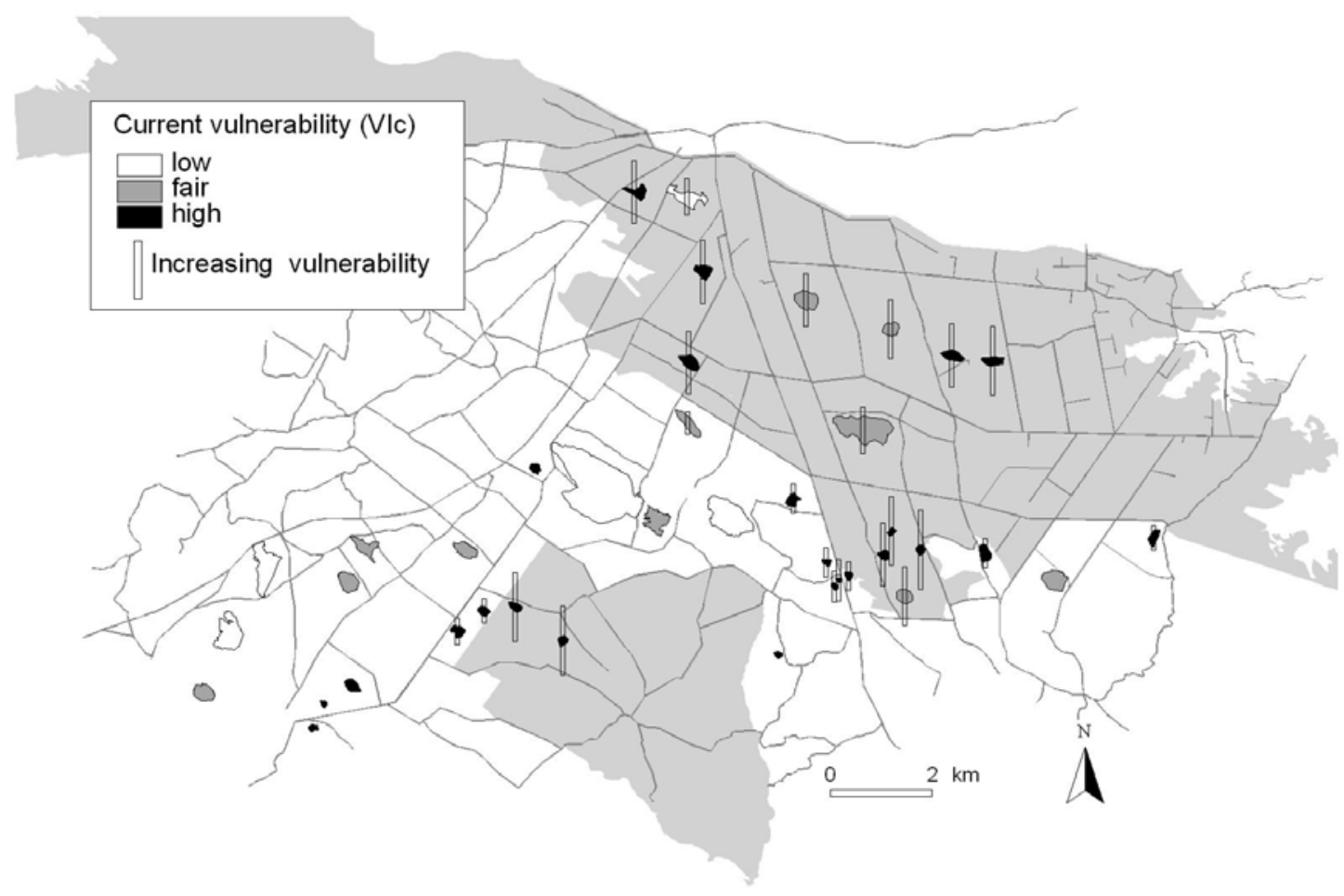



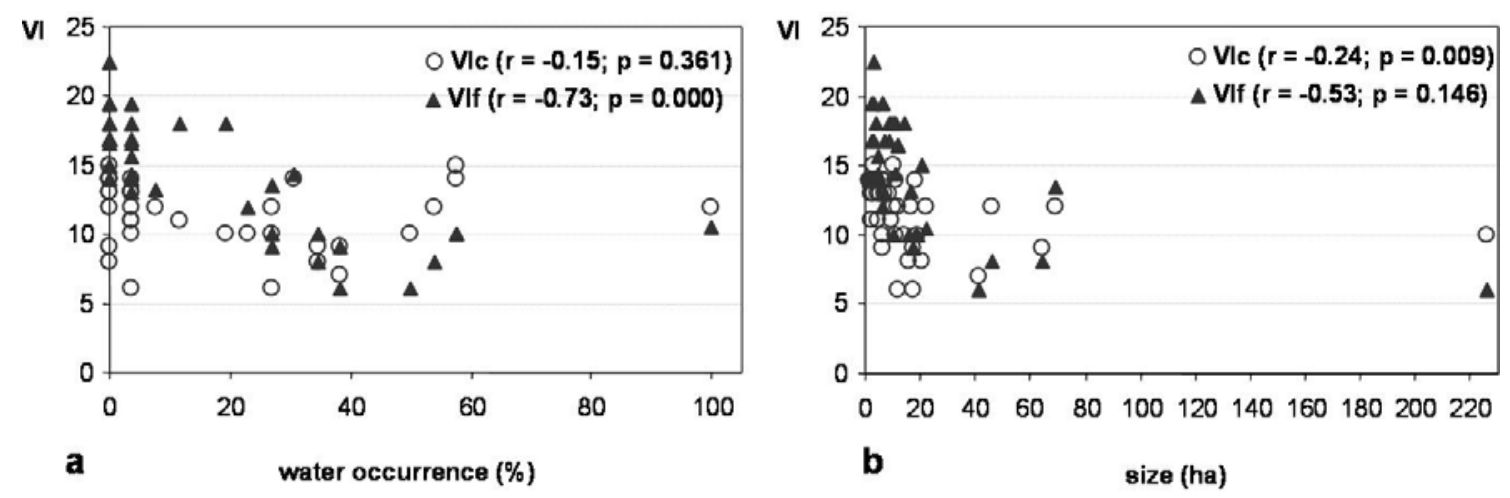


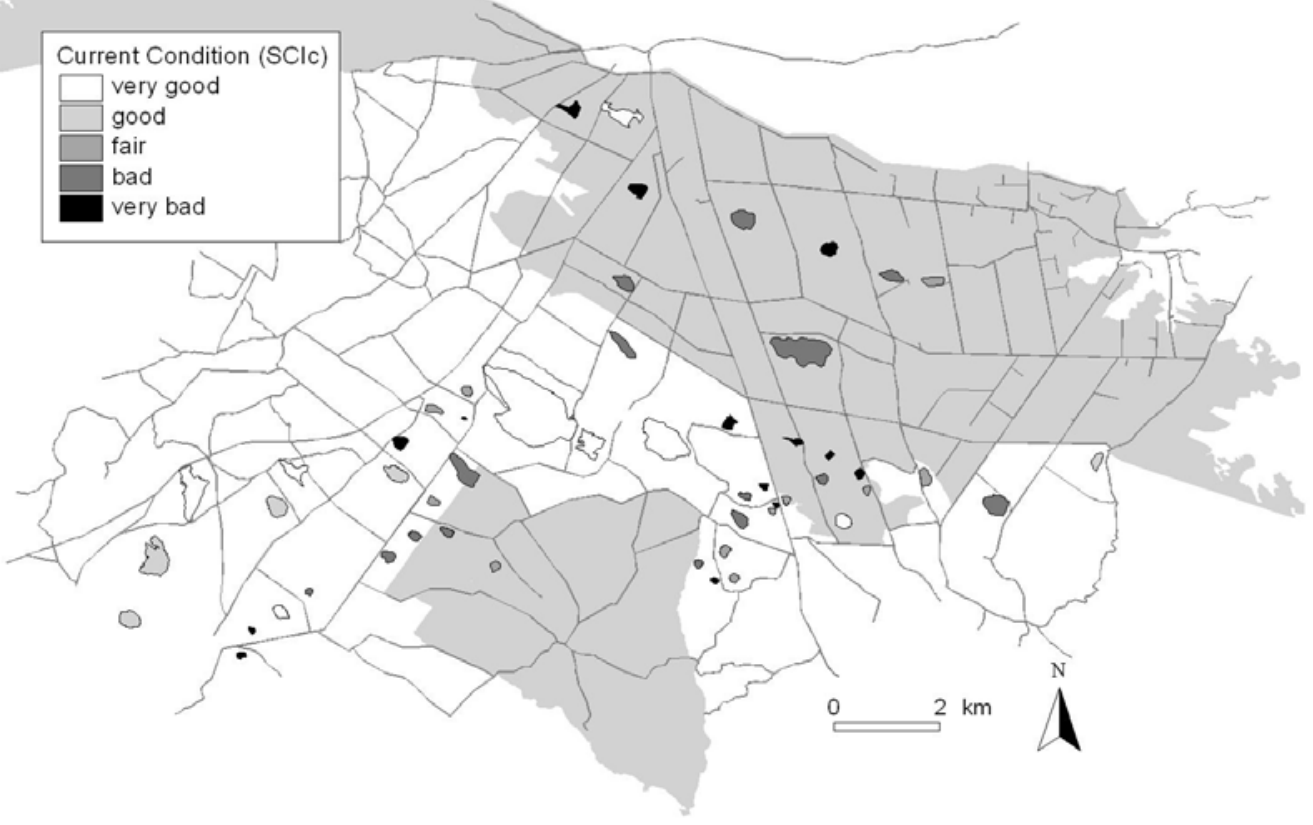

